\title{
A interação entre o trabalho educativo com software de geometria dinâmica e fotografia no ensino e aprendizagem de figuras geométricas
}

\author{
The interaction between educational work with dynamic geometry software and \\ photography in the teaching and learning of geometric figures
}

\author{
Viviane Aparecida de Souza \\ vivianesouza_2005@yahoo.com.br \\ Éliton Meireles de Moura \\ tommeireles@gmail.com \\ Janaína Fátima Sousa Oliveira \\ janainafsoufu@gmail.com \\ Arlindo José de Souza \\ arlindoufu@gmail.com
}

\begin{abstract}
Resumo
O trabalho analisa qual a viabilidade do uso de um software de Geometria Dinâmica no processo de ensinar e aprender Geometria no $5^{\circ}$ ano do Ensino Fundamental em uma escola pública. Sendo a análise das atividades feita na perspectiva das representações semióticas de Raymond Duval. Foram identificadas quais apreensões utilizadas em cada representação registradas pelos alunos nas etapas de resoluções das atividades. Considerou-se que o software foi um facilitador na visualização das propriedades das figuras geométricas. Além do software de Geometria Dinâmica, outro artificio tecnológico foi o uso de uma máquina fotográfica pelos alunos. $\mathrm{O}$ uso de programas computacionais ou outras ferramentas tecnológicas que possam automatizar a produção cognitiva de representações semióticas podem despertar o interesse e a inovação de um ponto de vista cognitivo e que explica o papel cada vez mais primordial que desempenham no ensino de matemática.
\end{abstract}

Palavras-chave: GeoGebra; Registros de representações semiótica; Séries iniciais; Apreensões em geometria; Fotografia.

\begin{abstract}
The paper analyzes which the viability of the use of a dynamic geometry software in the process of teaching and learning geometry in the 5th year of elementary school in a public school. As the analysis of the activities carried out from the perspective of semiotic representations of Raymond Duval. which seizures used in each performance recorded by the students on the steps of resolutions of activities have been identified. It was considered that the software has been a facilitator in view of the properties of geometric figures. In addition to the dynamic geometry software, other technological artifice was the use of a camera by the students. The use of computer programs or other technological tools that can automate the production of semiotic cognitive representations can spark interest and innovation from a cognitive point of view and explaining the role increasingly essential that play in the teaching of mathematics.
\end{abstract}

Keywords: GeoGebra; Records semiotics representations; Initial series; Seizures in geometry; Photography.

\section{Introdução}

A preocupação com o uso apropriado do laboratório de informática na rede pública, já é uma apreensão antiga dos educadores. Como afirmou Alvarenga em sua pesquisa: certas tecnologias ainda são muito recentes para determinados professores, as tornando, muitas 
vezes, subutilizadas (Alvarenga, 2011). Não que estejam utilizando de forma errônea, mais sem todo o seu potencial de uso.

Neste artigo procuramos analisar uma pratica coletiva de se implementar um trabalho educativo que possibilitasse ao estudante a interação com fotografias e um software de geometria dinâmica no processo de ensinar e aprender geometria na séries iniciais do ensino fundamental.

Nesta investigação enfrentamos o duplo desafio de incrementar práticas educativas com Tecnologias Digitais da Informação e Comunicação - TDIC no cotidiano da escola pública e o de investigar o processo de ensinar e aprender geómetria para estudantes do 5 ano do ensino fundamental. De acordo com Nacarato (2003, p.28) “a recuperação do ensino da geometria passou a ser, ao final dos anos 70, preocupação dos educadores matemáticos". Este fato, se faz presente nas propostas curriculares oficiais assim como no número de pesquisas sobre a geometria nos anos seguintes. Nacarato (2003, p. 28) cita a conferência intitulada "Perspectivas para o Ensino da Geometria no Século XXI", realizada na Catânia (Sicilia- Itália), em outubro de 95, como um exemplo desta preocupação crescente a respeito da complexa problemática envolvendo o ensino da geometria. Nesta conferência, discutiu-se os objetivos do seu ensino nos diferentes níveis escolares, de acordo com os diferentes ambiente e tradições culturais.

No ensino público temos na Prova Brasil uma avaliação externa, outro indicio desta mudança a respeito do olhar sobre o ensino da geometria. Esta avaliação "pode designar avaliação de uma instituição, realizada por profissional ou firma especializada neste tipo de consultoria, abrangendo todo o escopo ou apenas parte das ações institucionais" (WERLE, 2010, p.22), que envolve diretores, técnicos, professores e alunos das escolas públicas.

A Prova Brasil foi instituída pela Portaria ministerial $n^{0}$ 931, de 21 de Março de 2005, que institui o Sistema de Avaliação da Educação Básica - SAEB, sendo composto por dois processos de avaliação: a Avaliação Nacional da Educação Básica - ANEB, e a Avaliação Nacional do Rendimento Escolar - ANRESC, conhecida popularmente como Prova Brasil (Domingues e Oliveira, 2013).

Decorrente destas avaliações externas, o educador das séries iniciais hoje segue os conteúdos sugeridos na matriz de referência - SAEB (Sistemas de Avaliação da 
Educação Básica) Matemática de $5^{\circ}$ ano do Ensino Fundamental e seus descritores e temas.

Devido a esse conteúdo sugerido, encontramos um currículo que exige um desdobrar mais atencioso do professor para a geometria, como sugere no Guia de elaboração de Itens:

\begin{abstract}
identificar a localização ou movimentação de objeto em mapas, croquis e outras representações gráficas, identificar propriedades comuns e diferenças entre poliedros e corpos redondos, relacionando figuras tridimensionais com suas planificações, identificar suas propriedades comuns e diferenças entre figuras bidimensionais pelo número de lados, pelos tipos de ângulos, identificar quadriláteros observando as posições relativas entre seus lados (paralelos, concorrentes, perpendiculares), e finalmente, reconhecer a conservação ou modificação de medidas dos lados, do perímetro, da área em ampliação e/ou redução de figuras poligonais usando malhas quadriculadas. (Guia de Elaboração de itens, p.15, 2008)
\end{abstract}

É possível detectar nos itens propostos no guia uma quantidade de componentes da geometria que exige um preparo mais aprofundado do professor regente. Se o educador das séries iniciais a alguns anos atrás deixava a geometria para ser trabalhada nos últimos meses do ano, isso quando dedicava algumas horas aulas a geometria, conforme destaca Pavarello (1989) apud Nacarato (2007), citando um dos fatores que contribuiu para o abandono da geometria, foi um fator de ordem legal, pois a reforma da LDB (Lei 5692/71) permitia aos professores e escolas a montagens de seus próprios currículos, de acordo com as necessidades da clientela. Hoje o próprio PCN, assim como o incentivo dado pelo sistema de avaliação externa, exige que se trabalhe com mais dedicação os conteúdos geométricos.

Essas provas avaliam os conhecimentos de matemática e português nos quintos anos do ensino fundamental e nos nonos. As atividades propostas utilizam os descritores mencionados no Guia de Elaboração de itens e o seu resultado é classificado de acordo com o índice de desenvolvimento da educação básica (IDEB).

Sendo assim, as propostas das atividades realizadas no laboratório devem estar de acordo com o currículo que necessita ser apresentado aos alunos nesse nível de ensino.

Atualmente existem várias possibilidades de se trabalhar com a geometria. $\mathrm{O}$ uso do lápis, do compasso e da régua continua sendo uma delas, no entanto, é necessário haver a constante preocupação com a desmotivação. Com o advento da tecnologia, surgem novas maneiras de abordar o assunto. Denominada Geometria Dinâmica, softwares 
como Geogebra, Cabri-Géomètre, Cinderella entre outros, permitem a manipulação de figuras geométricas baseadas em suas propriedades.

\section{A Geometria e os processos cognitivos}

Duval (1998, p. 37-38) apud JANZEN nos orienta como devemos trabalhar a geometria. Para este autor, ao discutirmos a geometria é necessário considerar a complexidade cognitiva da atividade geométrica. A geometria envolve três tipos de processos cognitivos os quais tem funções epistemológicas específicas:

O primeiro deles é o processo de Visualização que se refere ao espaço de representação, ou seja, à ilustração de uma afirmação, à exploração heurística de uma situação ou uma verificação subjetiva;

O segundo, é o processo de construção por ferramentas onde a construção de configurações pode desempenhar o papel de um modelo que relaciona as ações sobre os resultados representados e observados aos objetos matemáticos que estão representados; e o último, é o processo de raciocínio relacionado a processos discursivos para a extensão do conhecimento, para a prova e explicação.

Duval afirma que embora esses processos possam ser realizados separadamente, eles estão entrelaçados e sua sinergia é cognitivamente necessária para se ensinar a geometria.

No entanto, Duval (1999) distingue três outras formas de interpretação de uma mesma figura: a apreensão discursiva, a apreensão sequencial e a apreensão operatória.

A apreensão perceptiva é imediata e espontânea, permitindo apenas constatações vistas de forma geral sem levar em conta os diferentes funcionamentos da figura. Para que a figura desempenhe um papel heurístico, é necessário vê-la de maneira mais profunda. Uma figura adquire um estatuto de figura geométrica quando: primeiro, é vista em relação a uma configuração (denominação, relação, etc), o que estaria relacionada à apreensão discursiva; e segundo, quando é construída a partir de ordens de construção, relacionada a apreensão sequencial. A apreensão discursiva de uma figura corresponde a uma explicitação de propriedades matemáticas como aquelas indicadas por hipóteses. Neste sentido, a figura é olhada a partir daquilo que é dado no enunciado, e são as propriedades matemáticas explicitadas que garantem às figuras o seu estatuto de figura geométrica. A função de apreensão sequencial é a reprodução da figura numa dada 
tarefa de construção; sendo que a apreensão perceptiva funciona apenas como um controle para determinar a coerência da construção da figura. (FLORES, 1997, p.31).

Em uma figura geométrica existem mais possíveis sub-configurações do que aquelas que estão explicitas em sua construção ou enunciadas como hipóteses. E é esse "excedente" que cria o poder heurístico das figuras, pois algumas sub-configurações dão as ideias chaves para uma explicação ou entendimento. Trata-se da apreensão operatória, que é centrada nas possíveis modificações de uma figura inicial e sobre as reorganizações perceptivas que estas modificações acarretam. Tal apreensão permite dar sentido dinâmico ás caraterísticas da figura, podendo-se fazer manipulações sobre o seu todo ou sobre parte da figura. (DUVAL, 1998, p. 41).

Pode-se observar, no entanto, que as várias apreensões não funcionam isoladamente, mas sim uma função da outra. Essa articulação entre elas que é importante para o ensino da geometria (DUVAL, 1997, p. 41):

- Entre apreensão perceptiva e discursiva (para ter o que chamamos de figura geométrica);

- Entre apreensão discursiva e sequencial;

- Entre apreensão perceptiva e operatória (o que corresponde a Visualização, sendo que para a visualização não é necessário a mobilização de teoremas ou proposições);

- Entre apreensão operatória e discursiva (que permite unir a heurística e a prova).

Como toda figura pode ser modificada de diversas formas, Duval $(1999$, p.12) também distingue três tipos de modificação: a modificação mereológica (consiste na divisão de uma figura em partes para em seguida combiná-las em outra figura), ótica (consiste em aumentar, diminuir ou deformar uma figura- problemas de homotetia ou perspectiva) e posicional (consiste no deslocamento da figura no plano em relação ao plano frontoparalelo).

A operação de reconfiguração é a que caracteriza a modificação mereológica: é uma operação que consiste em reorganizar uma ou várias subfiguras diferentes de uma figura dada em outra figura de contorno global diferente, ou seja, consiste na complementariedade de formas. É neste nível que esta operação intervém na produtividade heurística das figuras geométricas e se revela como uma operação fundamental para a apreensão matemática das figuras (DUVAL, 1999, p. 165).

Outro conceito importante a ser discutido quando se trata da geometria é o conceito figural. De acordo com Fischbein $(2002$, p.3) a geometria trata com entidades mentais - 
as chamadas figuras geométricas- que possuem características figurais e conceituais simultaneamente, pois as entidades as quais nos referimos em geometria (ponto, reta, ângulo, ou mesmo o triângulo e as operações que realizamos com eles) possuem qualidades conceituais. No raciocínio matemático não nos referimos a eles como objetos materiais nem como desenhos, são apenas modelos materializados das entidades mentais com as quais o matemático trabalha. Além disso, é apenas em um sentido conceitual que podemos considerar a perfeição absoluta de tais entidades geométricas, que possuem, então correspondentes materiais, sendo estes representações gerais e não cópias de objetos particulares e concretos.

Outra característica das figuras geométricas é que suas propriedades são impostas por definições, ou derivadas destas, em certo sistema axiomático. Deste ponto de vista, uma figura geométrica tem natureza conceitual- um quadrado não é apenas uma imagem desenhada em uma folha de papel, é uma forma controlada por uma definição. Assim, uma figura geométrica pode ser descrita como possuidora de propriedades intrinsecamente conceituais. Estes são os conceitos figurais, que possuem, portanto, duas componentes: conceitual e outro figural. O componente conceitual, com maior ou menor grau de formalismo baseado na linguagem natural e/ou simbólica, caracteriza certa classe de idealizações, generalizações, etc. Já a componente figural é de natureza visual (forma, posição, tamanho) e pode ser expresso através de um desenho.

Para Hoffer (1981), as habilidades visuais estão relacionadas à capacidade de ler desenhos e esquemas, de discriminar formas e de visualizar propriedades nelas contidas. As habilidades verbais envolvem a capacidade de expressar percepções, elaborar e discutir argumentos, justificativas, definições, descrever objetos geométricos e usar o vocabulário geométrico.

As habilidades de desenho contemplam a capacidade de expressar ideias por meio de desenhos e diagramas, fazer construções com régua, compasso, esquadro, transferidor e programas gráficos de computador. As habilidades lógicas, por sua vez, relacionam-se à capacidade de analisar argumentos, definições, reconhecer argumentos válidos e não válidos, dar contraexemplos, compreender e elaborar demonstrações. Finalmente, as habilidades aplicadas envolvem a capacidade de observar a geometria no mundo físico, apreciar e reconhecer a geometria em diferentes áreas tais como a arte. 


\section{Desenvolvimento do Trabalho Educativo}

A pesquisa teve como objetivo analisar uma sequencia de atividades desenvolvidas no laboratório de informática com o uso do GeoGebra, nas quais os alunos trabalharam as figuras geométricas com diferentes representações semióticas. Em específico pretendeuse verificar quais processos cognitivos estavam presentes nas atividades e quais eram as percepções presentes nesses processos. A análise cognitiva das questões consiste em decompor as soluções apresentadas em tratamentos segundo os registros mobilizados. Foram convidados a participarem deste estudo 30 alunos que cursavam o quinto ano do ensino fundamental nos anos de 2014 e 2015, totalizando 60 alunos e duas professoras regentes das turmas. Também houve a participação de uma equipe de pesquisadores os quais compunham um trabalho coletivo cujo intuito era buscar estratégias diferenciadas de ensino e aprendizagem sobre o uso de tecnologias na prática pedagógica. Esta equipe era composta por uma graduanda do curso de Licenciatura Matemática da Universidade Federal de Uberlândia, um Mestre em Educação Matemática, duas Mestrandas do curso de Ciências e Matemática da UFU que cursavam anos diferentes, entre elas a pesquisadora deste estudo laboratorista da escola pesquisada e um Doutor orientador das mesmas. Este estudo teve o subsídio da Fundação de Amparo a Pesquisa de Minas Gerais- FAPEMIG em parceria com a Coordenação de Aperfeiçoamento de Pessoal de Nível Superior- CAPES. Esta pesquisa foi caraterizada como uma pesquisa-ação e teve abordagem qualitativa.

Optou-se por apresentar, neste trabalho, uma atividade que tinha como tema central as Figuras Geométricas Planas: polígonos e circunfência. O objetivo principal era identificar/destacar nas paisagens/fotos as figuras Geométricas e nomeá-las utilizando o GeoGebra como Ferramenta. A professora pesquisadora disponibilizou para esta atividade a sua máquina digital.

Para o desenvolvimento da atividade os alunos foram divididos em 5 grupos. Cada grupo foi responsável por tirar 10 fotos do ambiente interno da escola nas quais eles enxergassem uma ou mais figuras geométricas.

Enquanto os alunos do grupo faziam o passeio no interior da escola para realizar o seu registro fotográfico os demais alunos continuavam no laboratório de informática com as atividades envolvendo o conteúdo de geometria, uma vez que era permitido apenas um grupo por ronda, pois havia uma única máquina para o registro das fotos. 
Figura 1: Registro feito pelos alunos

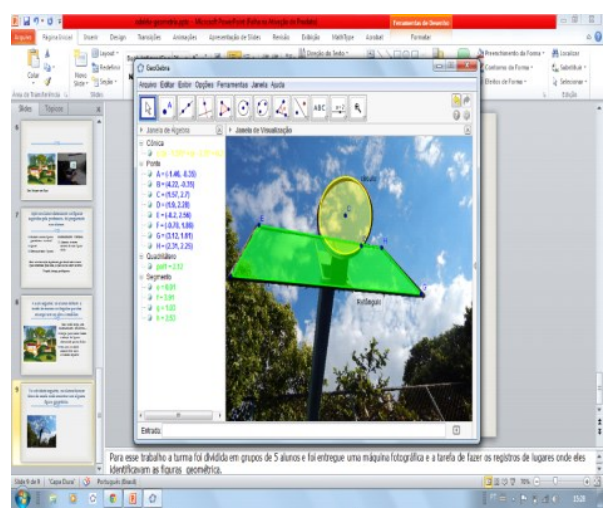

Figura 2: Modelo feito no GeoGebra

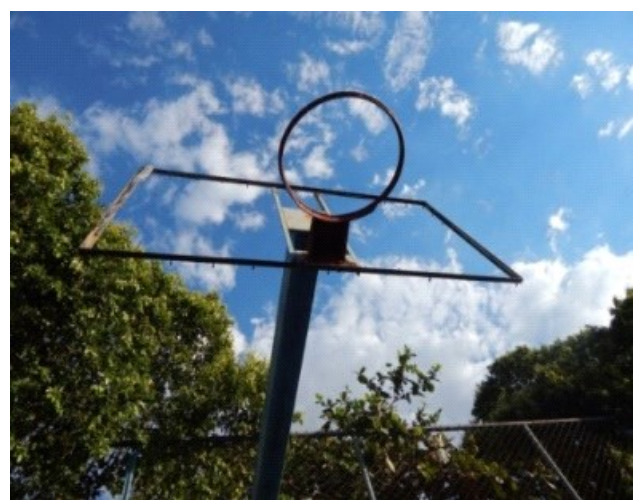

Segundo Nacarato e Santos (2014, p.33) o trabalho com a fotografia deve levar em conta o porquê de ter sido produzida e quem a produziu, ou seja, é necessário ter pistas suficientes para poder contextualizar as imagens. Neste sentido, o aluno conseguiria explicar o motivo de ter feito o registro de suas imagens destacando nelas as figuras geométricas que ele conseguia visualizar.

Esta atividade foi mais específica quanto ao uso de ferramentas do software de Geometria Dinâmica e do conhecimento geométrico. Foi pedido aos alunos que marcassem em 3 (três) fotos o mesmo polígono, utilizando para marcarem a ferramenta polígono. Poderia ser encontrada a mesma figura repetidas vezes na mesma foto, esta era uma das condições para a resolução da atividade.

De acordo com Gravina (2001) este tipo de atividade exige uma habilidade lógica, a qual consiste em perceber que há diferenças e semelhanças entre figuras. E principalmente, compreender a conservação da forma de uma figura em várias posições.

Figura 03: Trabalho feito no GeoGebra pelos alunos Cleber e Melissa.

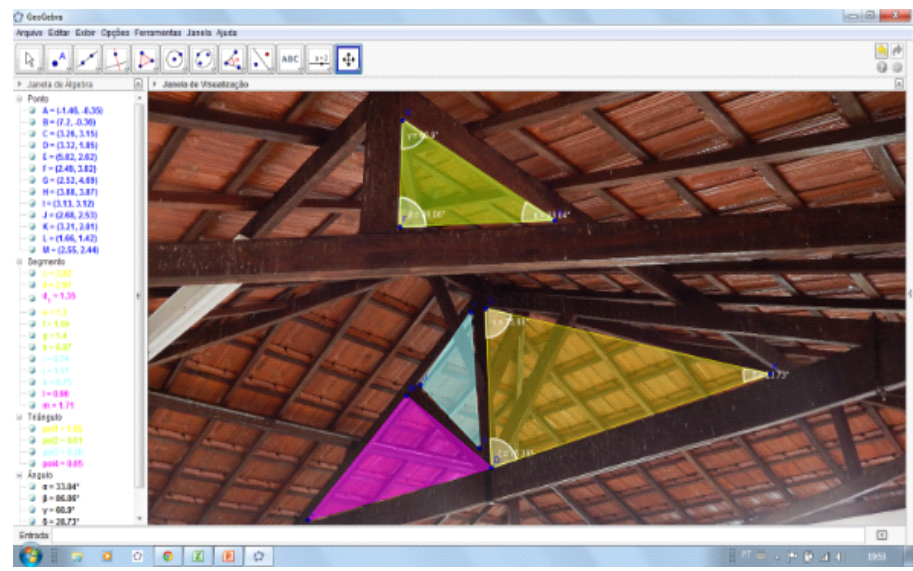


Foi pedido que utilizassem essa ferramenta, pois assim a figura não ficaria desconfigurada. A intenção dessa aula era que os alunos medissem os ângulos de todas as figuras, porém, não foi possível, o software não atendeu a esse plano de aula. Então ele foi modificado pedindo o trabalho apenas com triângulos.

No ano de 2015 esta mesma atividade foi refeita, porém as fotos foram postadas no blog criado por cada grupo para registrar as atividades desenvolvidas no laboratório de informática. Como eram muitas fotos, os alunos criaram um mosaico com as fotos para facilitar a manipulação e análise das mesmas.

Cada grupo deveria baixar e inserir o mosaico no GeoGebra, destacar em cada foto a figura geométrica em foco e nomeá-la. Esse destaque deveria ser feito utilizando uma ferramenta polígonos e modicando a cor da área interna da figura para posteriormente, nomeá-la.

Esse trabalho exigiu dos alunos uma habilidade de Aplicação: identificar formas geométricas nos objetos do ambiente.

\section{Resultados e Discursões}

Para que ocorra a aprendizagem de um conceito geométrico/matemático, a conceitualização do objeto matemático o qual Duval (2004, p. 14) nomeia de noesis deve ocorrer por meio de significativas representações, nomeado de semioses. Isso significa que a compreensão em matemática acontece na medida em que o sujeito que aprende consegue coordenar vários registros de representações associados a um mesmo objeto matemático ou geométrico.

O termo registro de representação semiótica é usado para designar os diferentes tipos de representação semiótica. As representações língua natural, figural, algébrica, gráfica são exemplos de diferentes tipos de registros de representações.

Um registro de representação semiótica é um sistema de signos que tem por objetivo não somente a comunicação, mas o tratamento da informação e a objetivação. Neste sentido, este registro de representação necessita permitir três atividades cognitivas: a formação de uma representação identificável, o tratamento de um registro de representação e a conversão de um registro para outro. (Duval, 2004)

Podemos analisar na nossa atividade geométrica por exemplo uma reta, ela é uma representação identificável, pois todos reconhecem esse signo, é comum a todos. A 
atividade cognitiva é cumprida. O tratamento é como formamos mentalmente a informação que conceitua a reta. As conversões por sua vez, são externas. Podemos representar uma reta de diferentes maneiras, seja graficamente, ou em forma de equação ou por nome.

Figura 04: Resultado final no GeoGebra do trabalho do grupo 5

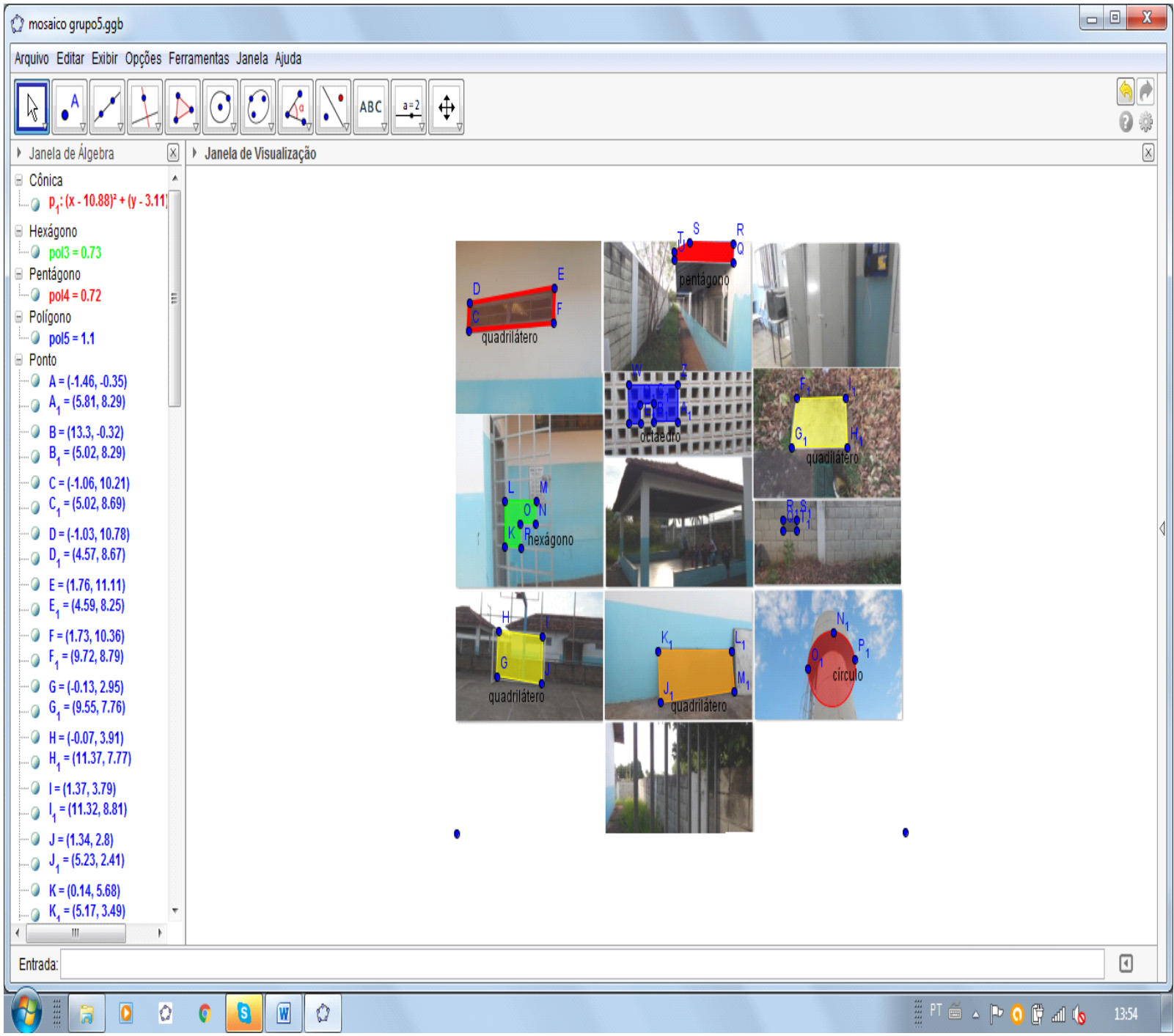

Esta atividade era a preferida do grupo de pesquisadores, pois o intuito inicial era desenvolver no GeoGebra várias atividades advindas destas fotos. No entanto, encontramos alguns entraves que serão melhores explicados no decorrer desta análise.

A primeira dificuldade que encontramos foi com relação à distorção promovida pela lente angular da máquina fotográfica. Por mais que aos olhos do aluno durante o registro fotográfico a imagem escolhida lhe parecesse um quadrado por exemplo, na imagem final da foto, essa imagem era modificada. 
Figura 05: Tipo de distorção promovida na fotografia

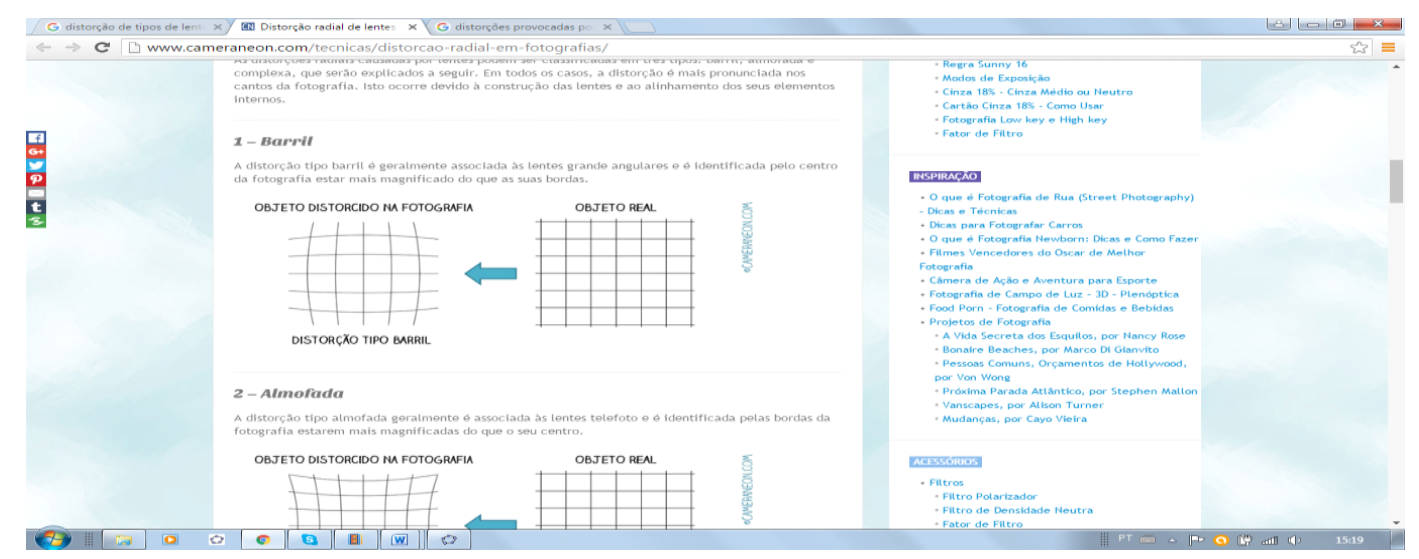

Nesta atividade podemos observar que o aluno ao ser exposto em seu ambiente escolar, seja no pátio, na quadra, nos entornos das salas de aula para procurar imagens que lhes lembrassem figuras geométricas, ele inicialmente está desenvolvendo um tipo de visualização para a exploração heurística importantíssima para o processo cognitivo da criança. Nesta situação, o aluno busca fazer um registro espacial, que dá lugar a formas de interpretações autônomas.

Este tipo de interpretação segundo Duval (2012a) pode ser classificado por apreensões. $\mathrm{Na}$ nossa atividade, destacamos a perceptiva, neste caso por exigir uma interpretação das formas das figuras geométricas; a operatória, pois esta centrada nas modificações possíveis de uma figura de partida e na reorganização perceptiva que essas modificações sugerem. No nosso caso, a apreensão operatória das figuras depende das modificações que a figura pode sofrer.

O tipo de modificação ocorrida em nossa atividade é classificado por Duval (2012a, 125) como sendo uma modificação ótica, ela transforma uma figura em outra, chamada a sua imagem. Esta transformação, que é realizada através de um jogo de lentes e espelhos, pode conservar sua forma inicial ou altera-la. Outra situação presente é a possibilidade de deslocá-la ou rotacioná-la em relação às referencias do campo onde ela se destaca: essa modificação é uma modificação posicional de orientação e do lugar da figura dentro de seu ambiente (em geral o plano fronto paralelo). Cada uma destas modificações o aluno é capaz de realizar mentalmente ou graficamente.

Nesta atividade o aluno teve que trazer da realidade, ou seja o 3D, para o plano de profundidade existente na fotografia $2 \mathrm{D}$ e posteriormente, nos traços das figuras simples fechadas visualizadas na tela do computador. Pois fazia parte da tarefa fazer o contorno da figura visualizada utilizando o GeoGebra. 
Outro ponto importante a ser destacado é a tomada de consciência do aluno ao absorver o conceito geométrico e ser capaz de utiliza-lo como sendo linguagem natural (registro discursivo).

Nas situações presentes nesta atividade, é possível destacar o uso de mais de um registro (as figuras geométricas, o discurso da língua natural, o uso gráfico das fotografias).

Neste caso utilizamos um tipo de tratamento das figuras geométricas chamado reconfiguração, segundo Duval (2012, p.272) é uma das numerosas operações que dá ao registro das figuras o seu papel heurístico. Nesta atividade analisada, quando o aluno consegue visualizar e destacar com cores diferentes partes de uma figura, mentalmente ele está utilizando a reconfiguração. Isso é percebido quando o grupo buscou no registro fotográfico encontrar um octaedro por exemplo, mostrado na figura 06 abaixo, ele foi capaz modificar a figura inicial a seu favor, no intuito de apresentar a solução da questão, ou seja diferentes polígonos.

Figura 06: Exemplo de reconfiguração

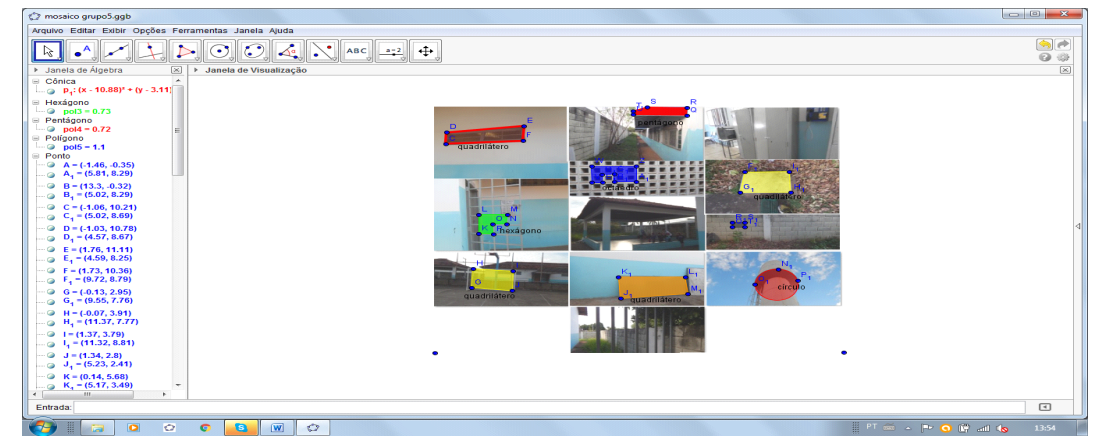

Este mesmo artificio foi utilizado na imagem do registro do outro hexágono, mostrado na figura 07 abaixo:

Figura 07: Outra situação de tratamento chamado de reconfiguração

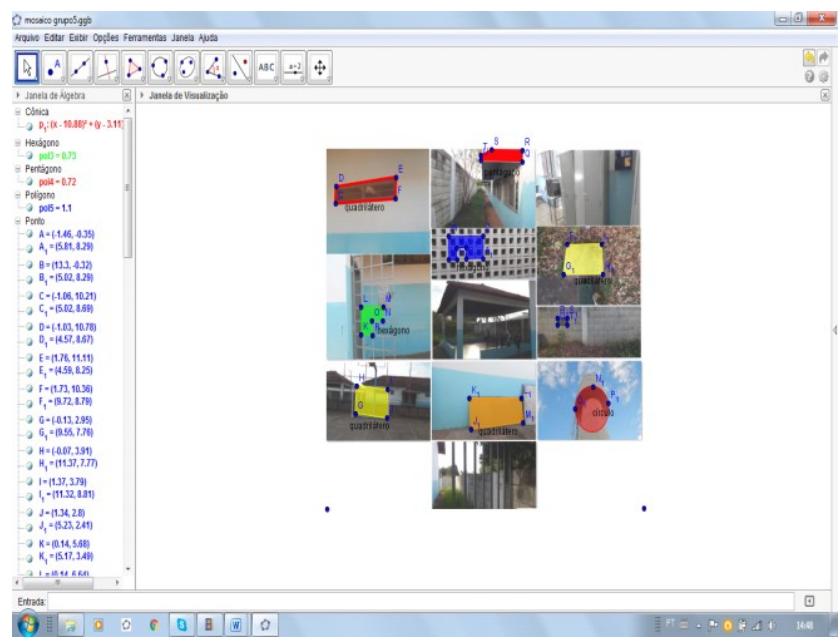


A anamorfose é uma forma de tratamento que se aplica a toda representação figural. No nosso caso, envolve a perspectiva da imagem promovida pelo registro fotográfico, no qual o aluno pode visualizar o mundo geometricamente, fazendo as conexões entre as figuras geométricas e as imagens fotográficas. A anamorfose pode ser percebida quando os alunos fizeram o registro de uma circunferência, e ao nosso olhar de observador da foto nos parece uma elipse por exemplo, ou quando um quadrado nos parece um paralelogramo ou losango dependendo da perspectiva do registro fotográfico Outra situação percebida foi o fato do reconhecimento inicial das figuras mais simples como os quadriláteros. No entanto, os alunos não conseguiam distinguir as variações dos quadriláteros: se era um quadrado, um retângulo, um losango ou paralelogramo. Fato que levou os pesquisadores posteriormente, a desenvolver uma atividade específica com os quadriláteros para que os alunos conseguissem na manipulação do software GeoGebra, distinguir as diferenças das propriedades de cada figura, trabalhando com os valores dos ângulos e comprimentos dos lados e paralelismo.

A intenção inicial desta atividade, era identificar as diferentes figuras com os cálculos dos ângulos internos e medidas dos lados, aprofundando com os conceitos das propriedades das figuras. No entanto, este tipo de atividade foi abandonada. Pois devido à distorção promovida pela lente angular, os registros mesmo sendo frontal, eram modificados oticamente, tornando impossível a representação figural por exemplo, de um quadrado, fato também explicado pela anamorfose. Se trouxéssemos para a tela do computador teríamos que fazer uma aproximação da figura e este fato nos desmotivou. Porém, foi possível em outras atividades, trabalharmos, por exemplo, a soma dos ângulos internos dos triângulos encontrados em fotos. Esse tipo de atividade exigia várias representações por parte do aluno. Pois ele deveria inicialmente, identificar os triângulos em posições variadas, o que cognitivamente é uma modificação posicional, além de ter que efetuar cálculos dos valores dos ângulos internos, posteriormente somar estes ângulos.

O grupo de pesquisadores eram cientes que este modelo de atividade não deve ser trabalhado no quinto ano do ensino fundamental, pois o conteúdo de medir ângulos não é ensinado nas séries finais do ensino fundamental I, no entanto, a facilidade promovida pelo software, dos cálculos dos ângulos facilitou o entendimento do conceito de ângulos e tornou possível o desenvolvimento deste tipo de atividade. 


\section{Considerações Finais}

Quando discutimos a respeito de figuras geométricas nos veem a mente os seus formatos, as suas propriedades. Essa construção na nossa mente esta relacionada com o conceito de visualização. De acordo com Moretti e Flores (2006, p. 5) é necessário "aprender a ver e a ler" as figuras, ou seja, essa visualização esta focada percepção e compreensão de imagens visuais. A figura neste contexto da visualização cumpre um papel importante, justamente por dar um suporte intuitivo e desempenhar uma função heurística. Duval (1999) complementa dizendo que o fato das figuras terem um papel intuitivo e heurístico na representação geométrica permitem analisar uma situação em conjunto, isto acontece pois são o meio mais direto para explorar os diferentes aspectos de um problema. Não significa visualizar apenas o que está posto na figura, exige a realização de reconfigurações possíveis, que podem englobar inclusive os conhecimentos matemáticos presentes no contexto.

A possibilidade de trabalhar com esta função heurística da figura, pode ser favorável ao aluno, podendo modificar sua forma de ver e entender a geometria. Para esse fim os softwares de geometria dinâmica têm grande potencial, uma vez que podem possibilitar a exploração desta função heurística, explorando a dinâmica envolvida no próprio conceito.

No entanto, é de suma importância salientar que o computador, a ferramenta computacional que permite o uso dos softwares de geometria dinâmica, nada mais é que um meio pelo qual a aprendizagem acontece. O grande mediador de tal feito continua sendo o educador, responsável por propostas de atividades que propiciem ao aluno fazer parte do processo, isto é, atuar junto à busca do conhecimento, especificamente, na aprendizagem matemática.

Há uma preocupação em se resgatar o ensino da geometria como uma das áreas fundamentais da matemática. Para isso, muitos estudiosos dedicam-se à reflexão, à elaboração, implementação e avaliação de alternativas que busquem superar as dificuldades que, muitas vezes, são encontradas na abordagem desse tema, principalmente pelos professores em sala de aula.

Nesse sentido, este trabalho propôs-se a elaborar e analisar a aplicação de atividades relacionadas ao estudo da geometria para alunos das séries iniciais do Ensino Fundamental I com o uso de um software de geometria dinâmica. Em especial esta atividade se mostrou essencial para que o aluno tenha a percepção de espaço, interprete esse espaço e sua representação de posição e de movimentação nele. Nesse processo, os 
pesquisadores atentam para a importância dos processos cognitivos existentes para o êxito do aluno nas atividades escolares, não só aquelas ligadas à matemática, mas a todas as outras áreas de estudo.

Quando aparece a chamada visualização, que é a articulação entre as apreensões perceptiva e operatória, percebe-se que a apreensão perceptiva é determinante para o sucesso ou fracasso da apreensão operatória. Ao construir uma figura, ou identificar propriedades de uma figura em uma foto, por exemplo, quando a criança, num primeiro olhar, identifica os contornos fechados da figura e classifica-a no espaço, a sua apreensão perceptiva auxilia a identificação. A mesma apreensão perceptiva será responsável pelo sucesso na execução da atividade quando o seu olhar for mais aprimorado.

A pesquisadora observou a dificuldade do uso do laboratório de informática pelos professores regentes. Eles foram peças importantes para o desenvolvimento desta pesquisa, no entanto, devido a essas observações, uso do software de geometria dinâmica seria apropriado após um treinamento por parte dos professores do ensino fundamental, para que os mesmos tenham maior segurança em desenvolver as atividades. Os alunos por sua vez, demonstraram curiosidade, facilidade no manuseio, perfeito domínio em todas as etapas das atividades. Houve parceria entre as duplas em todas as atividades.

Finalmente, tendo-se em vista o questionamento do problema que se apresentou para orientar o trabalho, que foi "compreender qual a viabilidade do trabalho com o software de Geometria Dinâmica no processo de ensinar e aprender Geometria no $5^{\circ}$ ano do Ensino Fundamental em uma escola pública?", pode-se afirmar que é viável o uso do software de Geometria Dinâmica. Cabe ao professor selecionar atividades que contemplem tanto apreensões quanto capacidades, de maneira que essa integração se dê de forma efetiva. A análise das atividades mostrou o quanto o uso do software instigou os alunos a terem confiança diante de uma situação problema, de tomar iniciativa e buscarem a solução. Eles mostraram confiança na capacidade de analisar e iniciativa para enfrentar algo novo ou desconhecido.

Duval (2015, p.5) afirma que para poder aprender em matemática é preciso fazer por si mesmo, ou seja é um tipo de conhecimento cuja prática permanece eminentemente individual. Por esse motivo, a ação interativa com o software de geometria dinâmica pode ser um facilitador da apreensão dos conceitos matemáticos. A partir do momento 
que o aluno consegue fazer descobertas, dar contraexemplos ele é capaz de ter sucesso na autonomia no que concerne a atividade matemática.

\section{Referências}

ABRANTES, P. (1999). Investigações em Geometria na sala de aula. In E. Veloso, H. Fonseca, J. Ponte e P. Abrantes (Orgs), Ensino da geometria ao virar do milénio. P. 51-62. Lisboa: Departamento de Educação da Faculdade de Ciências, Universidade de Lisboa.

ALVARENGA, C. E. A. Autoeficácia de professores para utilizarem tecnologias de informática no ensino. Tese (doutorado) U. E. de Campinas- Faculdade de Educação, SP; [s.n], 2011.

ALVES, Rosimar Pires. ARAÚJO. Doracina Aparecida de castro. Planejamento: organização, reflexão e ação da prática docente. Periódicos da UEMS. P. 389-396. 2009. Disponível em: http://periodicos.uems.br/novo/index.php/anaispba/article/viewFile/184/118 pesquisado em $12 / 11 / 15$

BRANDÃO. Ana Carolina e SELVA. Ana Coelho V.. O livro didático na educação infantil : reflexão versus repetição na resolução de problemas matemáticos. Revista educação e Pesquisa, São Paulo, v. 25, n. 2, p. 69-83, jul./dez. 1999. Pesquisado:< http://www.scielo.br/pdf/ep/v25n2/v25n2a06.pdf $>$

BRASIL. Secretaria de Educação Fundamental. Parâmetros Curriculares Nacionais : Introdução aos parâmetros curriculares nacionais / Secretaria de Educação Fundamental. Brasília : MEC/SEF, 1997. 126p.

D’AMBrosiO, Ubiratan. Educação Matemática da Teoria a Prática. (Coleção Perspectivas em Educação Matemática). Campinas, SP: Papirus, 1996.

DIRETRIZES CURRICULARES NACIONAIS GERAIS DA EDUCAÇÃO BÁSICA/ Ministério da Educação. Secretária de Educação Básica. Diretoria de Currículos e Educação Integral. - Brasília: MEC, SEB, DICEI, 2013.

DOMINGUES, Mauro Roberto de Souza. OLIVEIRA, Ney Cristina Monteiro de. A Avaliação Externa na Educação Básica e suas Implicações. Revista Encontro de Pesquisa em Educação Uberaba, v. 1, n.1, p.38-50, 2013. Pesquisado em http://www.revistas.uniube.br/index.php/anais/article/view/671/968

DOMINGUES, M. R. OLIVEIRA, N. C.M. A avaliação externa na educação básica e suas implicações. Trab42, evt2012, SBEC. 2012

DUVAL, R. Geometry from a Cognitive Point of View. In: C. Mammana e V. Villani (editores), Perspectives on the Teaching of Geometry for the $21^{5 t}$ Century, Dordrecth-BostonLondon: Kluwer Academic Publishers, p. 37-52, 1998.

La Géométrie et lês Variables de Visualisation, 1997.

Registros de representações semiótica e funcionamento cognitivo da compreensão em matemática. In: Aprendizagem em matemática: registros de representação semiótica. Organização de Silvia Dias Alcântara Machado, p.11- 33. Campinas, São Paulo: Papirus, 2003. 
.Abordagem cognitiva de problemas de geometria em termos de congruência. Revemat: R. Eletr. De Edu. Matem. elSSN 1981-1322. Florianópolis, v.07, n.1, p. 118-138, 2012a. Pesquisado em http://dx.doi.org/10.5007/1981-1322.2012v7n1p118

.Registros de Representação semiótica e funcionamento cognitivo do pensamento. Revemat: R. Eletr. De Edu. Matem. elSSN 1981-1322. Florianópolis, v.07, n.2, p. 266-297, 2012b. Pesquisado em http://dx.doi.org/10.5007/1981-1322.2012v7n2p266

.Mudanças, em curso e futuras, dos sistemas educacionais: Desafios e marcas dos $\overline{\operatorname{anos} 1060}$ aos anos .. 2030! Revemat: R. Eletr. De Edu. Matem. elSSN 1981-1322. Florianópolis, v.10, n.1, p.1-23, 2015. Pesquisado em http://dx.doi.org/10.5007/1981$\underline{1322.2015 \mathrm{v} 10 \mathrm{n} 1 \mathrm{p} 1}$

.Representation, Vision and Visualization: Cognitive Functions in Mathematical Thinking. Basic Issues for Learning. In: PME 21, 1999, México. Anais, México: 1999, vol.1, p. 3-26.

Semiósis e pensamento humano: registros semióticos e aprendizagens intelectuais. Trad. De Lênio Fernandes Levy e Maria Rosâni Abreu da Silveira. São Paulo: Livraria da Física, 2004, Coleção Textos da Ciência, fascículo 1.

Registros de representações semióticas e funcionamento cognitivo da compreensão em matemática. In: Machado, Silvia Dias Alcântra (org.). Aprendizagem em Matemática: registros de representações semiótica.4. Ed. Campinas: Papirus. 2003

Semiósis e pensamento humano: registros semióticos e aprendizagens intelectuais. São Paulo: Livraria da Física, 2009.

Semiosis y Pensamiento Humano- Registros Semioticos Y Aprendizajes Intelectuales. Colombia: Universidad del Valle, 1999

Ver e ensinar a Matemática de outra forma: entrar no modo matemático de pensar os registros de representações semióticas. Tradução de Marlene Alves Dias. São Paulo: PROEM, 2011.

FISCHBEIN, E. The theory of figural concepts. Educational studies in Mathematics, 24 (2), 1993. Tradução para o espanhol por Victor Larios Osorio, México, 2002.

FLORES, C. R. Geometria e Visualização: Desenvolvendo a competência heurística através da reconfiguração. Dissertação de Mestrado, Florianópolis, Universidade Federal de Santa Catarina, 1997.

FRANCO, M. A.S. Pedagogia da Pesquisa-ação. Educação e Pesquisa, São Paulo, v.31,n.3,p.483-502, set./dez.2005

FREUDENTHAL, H. (1973): Mathematics as an educational task. Dordrecht: D. Reidel Publishing Company.

FERREIRA, Emilia Barra et al, As Demonstrações no Ensino da Geometria: discussões sobre a formação de professores através do uso de novas tecnologias, Bolema, Rio Claro SP, Ano $22 \quad \mathrm{n}^{\mathrm{o}} \quad 34, \quad 2009, \quad \mathrm{pg} \quad 185 \quad$ a 2008 disponível em http://www.rc.unesp.br/igece/matematica/bolema/site34/9\%20\%As\%20Demonstra\%C3\%A7C3\%B 
GRAVINA, M. A. Geometria Dinâmica: uma nova abordagem para o aprendizado da geometria, em Anais do VII Simpósio Brasileiro de Informática na Educação, Belo Horizonte, 1996.

GRAVINA, Maria A. Os ambientes de geometria dinâmica e o pensamento hipotético dedutivo. Tese de doutorado em Informática na educação, UFRGS. Porto Alegre, 2001.

GUiA DE ELABORAÇÃo DE ITENS. Centro de Políticas Públicas e Avaliação da Educação da Universidade Federal de Juiz de Fora, 2008.

HEACOCK, P.; SOUDER, E.; CHASTAIN, J. Subjects, data and videotapes. Nursing, v. 45, n. 6, p. 336-338, 1996.

HOFFER, A. Geometria é mais que prova. Tradução de Antonio Carlos Brolezzi. Mathematics Teacher, NCTM, v.74, p.11-18, jan. 1981.

http://www.triangulomineiro.com/noticia.aspx? catNot=55\&id=8751\&nomeCatNot=Turis mo notícia do triângulo: Digitando o Futuro apresenta bons resultados, 29/03/09.

JANZEN, E. A. O papel do professor na formação do pensamento matemático de estudantes durante a construção de provas em um ambiente de geometria dinâmica. Tese apresentada ao curso de Pós-Graduação em Educação, Linha de Educação Matemática, Setor de Educação da Universidade Federal do Paraná. Curitiba, 2011.

KENSKI, V. M. Aprendizagem mediada pela tecnologia. Revista Diálogo Educacional, Curitiba, v. 4, n. 10, p. 47-56, 2003.

LÜDKE, M.; ANDRÉ, M. E. D. A. Métodos de coleta de dados: observação, entrevista e análise documental. In: EPU, 1986, p.25-44. Pesquisa em educação: abordagens qualitativas. São Paulo:

MEDEIROS, Ana Claudia J. P. Análise das Políticas de Inclusão Digital na rede pública municipal de ensino de Uberlândia no período de 1999-2012. Dissertação (mestrado) Universidade Federal de Uberlândia, Programa de Pós-Graduação em Educação. 2013

MENEZES, Douglas C. Desenvolvimento da Cultura Digital na formação inicial do professor de matemática. Dissertação (Mestrado)- Universidade Federal de Uberlândia, Programa de Pós -Graduação em Educação, 2014.

MERRIAN, S. B. Case study Research in Education: a Qualitative Approach. San Francisco. Jossey Bass. 1998.

MORAN, José Manuel; MASETTO, Marcos T.; BEHRENS, Marilda Aparecida. Novas tecnologias e mediação pedagógica. 14 ${ }^{\mathrm{a}}$ Ed. Campinas, SP. Papirus, 2008.

MORETTI, M. T. ; FLORES, C.R. As figuras geométricas enquanto suporte para a aprendizagem em geometria. Um estudo sobre a heurística e a reconfiguração. REVEMAT, Universidade Federal de Santa Catarina, v. 11, p. 5-13, 2006.

NACARATO, A. M. O ensino de Geometria nas séries iniciais. In: IX Encontro Nacional de Educação Matemática, 2007, Belo Horizonte. Diálogos entre a pesquisa e a prática educativa. Belo Horizonte : SBEM e SBEM/MG, 2007. v. 1. p. 1-18.

et al. A geometria nas séries iniciais: uma análise sob a perspectiva da prática pedagógica e da formação de professores. /Adair Mendes Nacarato, Carmem Lucia Bancaglion Passos. - São Carlos: EdUFSCar, 2003. 
NACARATO, A. M. e SANTOS, C. A. A aprendizagem em geometria na educação básica: a fotografia e a escrita na sala de aula. 1.ed. Belo Horizonte: Autêntica Editora, 2014.

NUNES, José Messildo Viana. A prática da argumentação como método de ensino: o caso dos conceitos de área e perímetro de figuras planas. 2011. 220 f. Tese (Doutorado em Educação) - Pontifícia Universidade Católica de São Paulo, São Paulo, 2011.

PARÂMETROS CURRICULARES NACIONAIS: terceiro e quarto ciclos do ensino fundamental: Introdução aos Parâmetros Curriculares Nacionais / Secretaria de EducaçãoFundamental. - Brasília: MEC/SEF, 1998.

PRENSKY,M. Digital natives, digital immigrants, Part 1. On the Horizon, v.5, n.9, p. 2-6, sept./oct.2001.

REY. F. G. Pesquisa Qualitativa e Subjetividade: os processos de construção da informação. Tradução [Marcel Aristides Ferrada Silva]. São Paulo Pioneira Thomson Learning, 2005.

RIBEIRO, A.L. O papel da escola básica como agência promotora do letramento digital. EHum, Belo horizonte, v.3, n.1, p. 1-15, 2010.

SILVA,R.M.G. A possível contribuição da aprendizagem escolar sobre conceitos de química no desenvolvimento intelectual das crianças nas séries iniciais. Ijuí: Ed. Unijuí, 1998.

ZILLI, Silvana do Rocio. A Robótica Educacional no Ensino Fundamental: Perspectivas e Prática. 89 f. Dissertação (Mestrado em Engenharia de Produção) - Programa de Pós-Graduação em Engenharia de Produção, UFSC, Florianópolis, 2004. 